\title{
Tratamento fisioterapêutico para instabilidade articular nas entorses de tornozelo
}

A prevalência da entorse de tornozelo em indivíduos não atletas, atletas amadores e profissionais é alta, sendo especificamente um distúrbio muito comum do sistema musculoesquelético nos membros inferiores de acordo com os estudos citados no trabalho. A entorse de tornozelo é frequentemente uma lesão causada por trauma em inversão excessiva do pé, podendo a mesma ser classificada por meio deste mecanismo de lesão. Com alta prevalência de instabilidade articular persistente, a entorse de tornozelo apresenta trauma recidivo em vários casos, justificando assim a cronicidade do quadro. $\mathrm{O}$ objetivo do trabalho foi estabelecer as relações entre a entorse de tornozelo com o quadro desenvolvido de instabilidade articular e o tratamento fisioterapêutico em indivíduos atletas e não atletas com este tipo de lesão. O recurso metodológico do trabalho foi uma revisão bibliográfica da lesão e a conduta fisioterapêutica, onde foram selecionados artigos e livros relevantes, correlacionando a prevalência das entorses de tornozelo e a instabilidade articular, propondo o tratamento fisioterapêutico e não sendo objetivado aqui o quadro geral das entorses de tornozelo, mas sim na instabilidade articular. A conclusão do trabalho confirmou a alta prevalência de instabilidade articular crônica nas entorses de tornozelo e ainda se evidenciou o tratamento fisioterapêutico baseado em fortalecimento muscular e treinamento proprioceptivo como conduta eficaz para este quadro clínico.

Palavras-chave: Entorse de Tornozelo; Instabilidade Articular; Fisioterapia.

\section{Physiotherapeutic treatment for articular instability in ankle sprains}

The prevalence of ankle sprains in non-athletes, amateur and professional athletes is high, being specifically a very common disorder of the musculoskeletal system in the lower limbs according to the studies cited at work. Ankle sprain is often an injury caused by trauma in excessive inversion of the foot, which can be classified through this injury mechanism. With a high prevalence of persistent joint instability, ankle sprains have recurrent trauma in several cases, thus justifying the chronicity of the condition. The aim of the study was to establish the relationship between ankle sprain and the developed joint instability and physical therapy treatment in athletes and non-athletes with this type of injury. The methodological resource of the work was a bibliographic review of the injury and the physiotherapeutic conduct, where relevant articles and books were selected, correlating the prevalence of ankle sprains and joint instability, proposing the physiotherapeutic treatment and the general picture of the sprains is not aimed at here. ankle, but in articular instability. The conclusion of the study confirmed the high prevalence of chronic joint instability in ankle sprains and physiotherapeutic treatment based on muscle strengthening and proprioceptive training was also shown to be an effective approach for this clinical condition.

Keywords: Ankle Sprain; Joint Instability; Physiotherapy.

\section{Topic: Fisioterapia}

Reviewed anonymously in the process of blind peer.
Received: $19 / 02 / 2020$

Approved: 04/05/2020
Sandro Emílio Vieira (iD

Universidade Católica de Petrópolis, Brasil

http://lattes.cnpq.br/9794817143053825

http://orcid.org/0000-0003-1618-3529

sandro.vieira@ucp.br

Matheus da Silva Rezende (iD

Universidade Católica de Petrópolis, Brasil http://lattes.cnpq.br/9016664173700262 http://orcid.org/0000-0003-4287-9909 matheusrzds@gmail.com

\section{Referencing this:}

VIEIRA, S. E.; REZENDE, M. S.. Tratamento fisioterapêutico para instabilidade articular nas entorses de tornozelo. Scire Salutis, v.10, n.2, p.9-17, 2020. DOI: http://doi.org/10.6008/CBPC2236$\underline{9600.2020 .002 .0002}$ 


\section{INTRODUÇÃO}

A entorse vem do latim exprimere, que significa "pressionar para fora" e sendo assim, no corpo humano essas lesões ocorrem nas articulações e nas estruturas que estabilizam as mesmas, entre elas os ligamentos, que podem sofrer distensões ou rupturas de modo parcial ou total (TAKAHASI et al., 2004). A articulação do tornozelo é uma estrutura que tem em seu âmbito algumas articulações tornando-a um complexo articular, onde se apresentam as articulações tíbio-fibular, talo-crural, tibiotársica e subtalar. Possui dentre outros, dois conjuntos ligamentares de suma importância: medialmente o ligamento deltóide (com suas divisões) e lateralmente os ligamentos talofibulares anterior e posterior e calcâneofibular. Sendo este último aqui citados as estruturas mais acometidas nos traumas do tipo entorse do tornozelo (MOREIRA et al., 2008).

A entrose de tornozelo tem uma alta prevalência nas lesões traumato-ortopédicas, apresentando ainda como um fator complicador o fato desta articulação ter importante função de sustentação corporal. Pode-se justificar que a maior ocorrência das entorses de tornozelo em inversão é devido à instabilidade fisiológica maior conferida pelos ligamentos laterais do tornozelo em comparação ao complexo ligamentar medial desta articulação, assim como a própria congruência articular que oferece mais mobilidade para a inversão do que para a eversão (HALL, 2016). Starkey et al. (2001), Hebert et al. (2003), Zampieri (2000) e Lasmar et al. (2002) também afirmam que a lesão do tipo entorse do tornozelo é de maior incidência com o pé em inversão. Para Baroni (2010), a entorse nesta articulação é uma das lesões musculoesqueléticas aguda mais recorrentes no mundo, onde os dados epidemiológicos citam a prevalência de 1 cada 10.000 pessoas por dia. Ainda em suas prevalências, a entorse de tornozelo é mais comum em atletas e pessoas com vidas ativas, com maior frequência em inversão do pé por meio de movimentos bruscos e rápidos, levando ou não ao rompimento de ligamentos (ZAMPIERI et al., 2003). Cerca de $40 \%$ das entorses de tornozelo ocorridas com os indivíduos fazem com que os mesmos apresentem instabilidade articular, ou seja, esse tipo de lesão pode acarretar em problemas secundários ou mesmos em novos episódios de entorse (HEBERT et al., 2003).

A entorse de tornozelo chega ao percentual $24 \%$ de todas as lesões em atletas, e em relação ao atendimento na urgência e emergência em hospitais temos índice de 14\% (O'DRISCOLL et al., 2011; FORTES et al., 2008). Os tipos de atividades esportivas que tem maior incidência com essa lesão são o futebol, vôlei, basquete e balé (GARRICK, 2001). As lesões ocorridas no esporte são o segundo tipo que se apresenta de maneira mais frequente, sendo que a segunda área do corpo que mais ocorre lesões na pratica esportiva é no tornozelo, e nessa articulação se tem com maior ocorrência a entorse de tornozelo lateralmente (NORONHA et al., 2012; O'DRISCOLL et al., 2011).

De acordo com Santos et al. (2007), as atividades esportivas que remetem ao salto, de $15 \%$ a $45 \%$ são lesões de tornozelo, que correspondem a $25 \%$ de ausência de atletas em treino e jogos devido a lesão. Segundo Fong et al. (2009), a lesão na pratica esportiva pode levar vários fatores subsequentes como despesas financeiras médicas, presença de dor, perda do tempo e produtividade relacionado a aquela atividade, e pontuando sobre a área do tornozelo as lesões ocorridas podem resultar em instabilidade 
funcional, fraturas ósseas, diminuição de força muscular, diminuição da propriocepção, limitações na mobilidade e déficit em realizar a pratica esportiva ou até levar a interrupção total da mesma. Evidencia-se a premência de introduções de medidas profiláticas colocadas para utilização por técnicos e professores frequentemente com intuito de diminuir o risco de lesão ao decorrer do tempo de treinamento (ARENA et al., 2005).

Por Lasmar et al. (2002), o rompimento ou estiramento dos ligamentos laterais do tornozelo, desequilíbrio subtalar, debilidade dos tendões fibulares, desequilíbrio subtalar, modificações proprioceptivas e variáveis anatômicas são os pontos principais que podem levar a ocorrência de modificações mecânicas e neuromusculares. A nomenclatura entorse se correlaciona a lesão de ligamentos, entretanto não unicamente essas estruturas que sofrem essa lesão, relatos clínicos indicam o comprometimento do sistema musculoesquelético e do sistema nervoso periférico em pessoas que sofreram tal lesão (HEBERT et al., 2003).

\section{METODOLOGIA}

Consistirá em uma revisão de literatura, que segundo Prado et al. (2013), consiste em iniciar um levantamento teórico através de fontes como: artigos científicos, livros, dissertações, monografias, relatórios de pesquisas e teses de modo amplo, com o intuito de formular a contextualização da pesquisa e seu embasamento teórico, sendo o mesmo parte do referencial da pesquisa de forma de uma revisão de literatura (ou referência bibliográfica), procurando identificar o 'estado da arte' ou o alcance de tais fontes.

Tais medidas mostrarão até que linha foi estudado esse tema e pontuado na literatura relevante, também pode-se estabelecer um marco teórico de referência (objetividade do conhecimento que se refere aos modos de observação e experimentação, ponto de corte epistemológico-estabelecimento dos níveis de reflexão) e seu alcance em termos temporais. Em tal ponto, se analisa as obras cientificas mais recentes e disponíveis que abordam sobre o tema, que proporcionem o embasamento metodológico e teórico para desenvolver do projeto de pesquisa, sendo que também são pontuados os principais termos técnicos e conceitos para se utilizar na pesquisa. A revisão de literatura evidencia que o pesquisador está de modo atualizado as discussões mais atuais sobre o campo de conhecimento que se encontra em investigação, e além de livros, artigos internacionais e nacionais já publicados, as dissertações, teses e monografias proporcionam excepcionais fontes para consulta.

\section{DISCUSSÃO TEÓRICA}

De acordo com Zampieri (2003), a avaliação fisioterapêutica tem etapas subsequentes que enquadrariam os procedimentos a seguir. Na coleta de dados da história, os pacientes que sofreram entorse têm sua história coligada ao mecanismo de lesão, referindo 'torcido o pé para dentro e para baixo', descrevendo de modo simples a inversão de tornozelo com flexão plantar. Ainda baseado no autor acima, no exame físico de inspeção se deve primeiramente observar o paciente de maneira geral, verificando posturas antálgicas tanto na posição ortostática estática quanto em deambulação. A palpação se associa a inspeção local na busca por quadro álgico, alteração da temperatura e análise de possível edema. 
Os exames complementares podem ser realizados através de exames de imagem como a radiografia que se verifica a presença de algumas outras lesões associadas ao trauma, como fraturas por avulsão da tíbia, fíbula e do tálus, e fraturas osteocondrais relacionadas ao tálus. Para verificar a mais sobre a extensão as artrografias com contraste ajudam na coleta de informações para o caso, podem-se utilizar exames de imagens mais sofisticados como a ressonância magnética para analisar tecidos moles, todavia por questões financeiras não são tão utilizadas, e sendo a maior parte dos casos de entrose de tornozelo analisada por meio de radiografia por médicos qualificados (ZAMPIERI, 2003).

São diversos métodos de classificação para as entorses primárias relatadas na literatura, tais métodos têm como base o funcionamento articular e no comprometimento do completo dos ligamentos na parte lateral do tornozelo, pontuados clinicamente. Segue abaixo o quadro de classificação de acordo com Zampieri (2003).

Quadro 1: Classificação das entorses de tornozelo.

\begin{tabular}{|l|l|l|l|}
\hline Grau I & Entorse leve & $\begin{array}{l}\text { Presença de edema leve, perda funcional sutil e sem alterações na } \\
\text { amplitude de movimento articular }\end{array}$ & $\begin{array}{l}\text { Há pouca lesão } \\
\text { ligamentar }\end{array}$ \\
\hline Grau II & $\begin{array}{l}\text { Entorse } \\
\text { moderado }\end{array}$ & $\begin{array}{l}\text { Paciente refere sentir dor moderada, edema, alguma perda de funcional } \\
\text { e moderado aumento da amplitude articular fisiológica }\end{array}$ & $\begin{array}{l}\text { Há ruptura ligamentar } \\
\text { parcial }\end{array}$ \\
\hline Grau III & $\begin{array}{l}\text { Entorse } \\
\text { severo }\end{array}$ & $\begin{array}{l}\text { Presença de edema severo, dor, equimose, perda da função articular. } \\
\text { Podem ser observadas amplitudes de movimentos consideravelmente } \\
\text { anormais no tornozelo }\end{array}$ & $\begin{array}{l}\text { Nesse estágio há } \\
\text { ruptura completa dos } \\
\text { ligamentos }\end{array}$ \\
\hline
\end{tabular}

Fonte: Zampieri et al. (2003).

Segundo Starkey et al. (2001), a realização dos testes específicos tem o objetivo de causar estresse no complexo ligamentar da área do tornozelo de maneira passiva, enfatizando no momento do movimento da articulação a área que a dor está localizada e relacionando com cada estrutura testada. Cook et al. (2015) apresentam os seguintes testes como indicações para análise de instabilidade do tornozelo: Teste de Translação Fibular, Teste de Rotação Lateral, Teste do Algodão, Teste de Gaveta Anterior e Teste de Deslocamento Medial da Articulação Subtalar.

Cerca de $40 \%$ das entorses ocorridas com os indivíduos os levaram a apresentar instabilidade articular, o que é uma condição facilitadora para o surgimento de problemas secundários como novos episódios de entorse, fraturas, luxações e outras (HEBERT et al., 2003). No que tange a instabilidade articular os autores citados neste paragrafo classificam a mesma de duas formas: (A) Funcional, onde há um relato do próprio paciente com sensação de 'falseios', geralmente associada à entorse recidivante e dor na área. 0 falseio é entendido como uma referência a uma não continuidade adequada do movimento quando de maneira brusca; (B) Mecânica, sendo pontuada a mobilidade excessiva na articulação e ainda, a radiologia apresentará achado de aumento das distancias entre as estruturas anatômicas. Pode-se estar correlacionada a entorses recorrentes ou não, com evidente déficit da estabilidade local.

Para os casos de entorse de tornozelo, o tratamento fisioterapêutico frequentemente e precedido por período de imobilização e uso associado de medicamento ou até mesmo de procedimento cirúrgico para reparo das lesões estruturais causadas pelo trauma. Contudo, como o objeto de estudo deste trabalho é a atenção fisioterapêutica a este agravo, dedicamos a seguir as intervenções da Fisioterapia para a 
instabilidade crônica do tornozelo lesionado seguidamente pelas entorses. Os trabalhos pesquisados demostraram uma alta prevalência de intervenções com exercícios proprioceptivos e resistido, sendo estas abordagens de tratamento aquelas as quais este trabalho se dedicou.

A nomenclatura "propriocepção" no começo foi pontuada e descrita em 1906, e a partir de então foi vastamente utilizada no que se refere a reabilitação dos indivíduos com lesões ou patologias (SHERRINGTON, 1906, citado por LEPORACE et al., 2009). De acordo com Guyton et al. (2006) pontuou-se que através de vias aferentes, vias estas que se direcionam ao sistema nervoso central, as informações proprioceptivas se deslocam, sendo que no sistema nervoso central são processadas e programadas para novas maneiras de ativar a musculatura para estabilizar as articulações.

Segundo Solomonow et al. (2001), o controle neuromuscular é a preparação e a resposta ao movimento articular, recorrente da ativação de modo inconsciente dos estabilizadores dinâmicos. Através de uma lesão ligamentar se pode ocorrer um ciclo recorrente de lesões, devido ao fato que por meio da mesma pode ser gerada a instabilidade mecânica, diminuindo assim sua consciência proprioceptiva. Como consequência, ocorre alterações no controle neuromuscular, alterações estas como maximizam as instabilidades mecânica e funcional, cronificando o quadro mantendo o indivíduo predisponente para novas lesões (FELLOWS et al., 1989, citado por LEPORACE et al., 2009). A captação de informações proprioceptivas é por meios de receptores musculares, sendo esses o OTG (Órgão Tendinoso de Golgi) e o fuso muscular, e receptores articulares localizados na capsulas e ligamentos das articulações (HOGERVORST et al., 1998; WILLIAMS et al., 2001).

É apresentado que os exercícios proprioceptivos têm enorme atuação na profilaxia e reabilitação em ocorrências de lesões musculoesqueléticas, devido a demanda da especificidade sensorial de modo mais acentuado em nível de competência para adquirir informações referidas a sensação ao movimento e sua localização articular, baseado em princípios de outros coeficientes que não o auditivo, visual ou cutâneo superficial. Por meio de treinamento, pode-se obter um aumento da competência do segmento corporal para se localizar no espaço, perceber o ângulo articular e a velocidade da mudança deste ângulo, para assim modificar seu mapeamento proprioceptivo (motor). Sendo esclarecido nos estudos e literatura, que o risco de lesões esportivas está relacionado aos parâmetros de controle neuromuscular, propriocepção, força, equilíbrio, flexibilidade e habilidades, de fato as estratégias preventivas são recomendadas e aplicadas para diminuir tais fatos (EMERY, 2005). Seguem agora cinco exercícios proprioceptivos indicados e retirados do livro: Exercícios Terapêuticos - Fundamentos e Técnicas (KISNER et al., 2016).

No que se refere ao tratamento resistido, de acordo com Kisner et al. (2016), o treinamento resistido ou exercício resistido é conceituado como a realização do exercício ativo de modo que tem a presença da contração muscular sendo tal qual dinâmica ou estática ocorrendo a resistência por via de fator externo por colocação manual ou mecânica, de forma essencial o exercícios resistido é um ponto chave para os programas de condicionamento para promoção e preservação da saúde, aumentando as competências motoras e diminuindo o risco relacionado com patologias e lesões. 

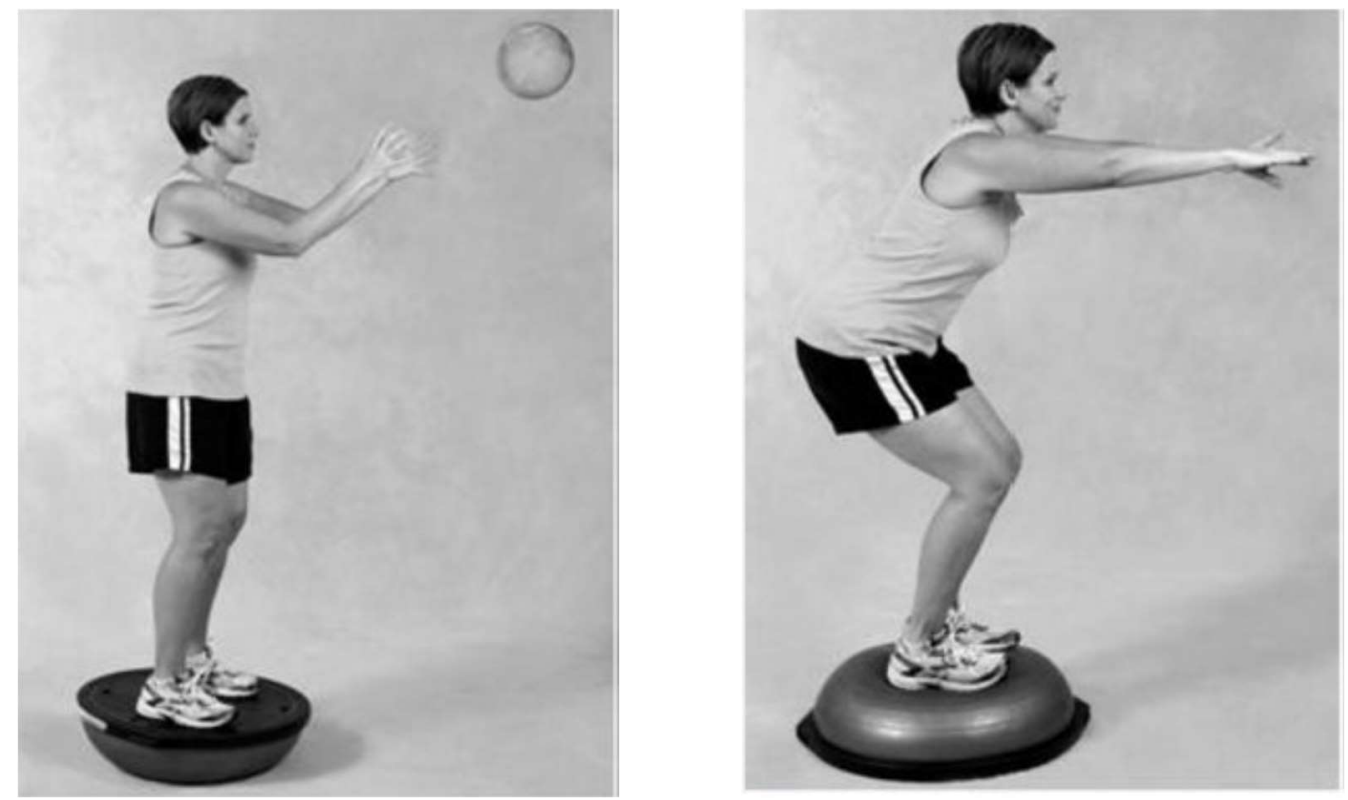

Figura 1: Equilíbrio bilateral sobre um bosu. Figura 2: Agachamento sobre uma superfície instável. Fonte: Kisner et al. (2016).
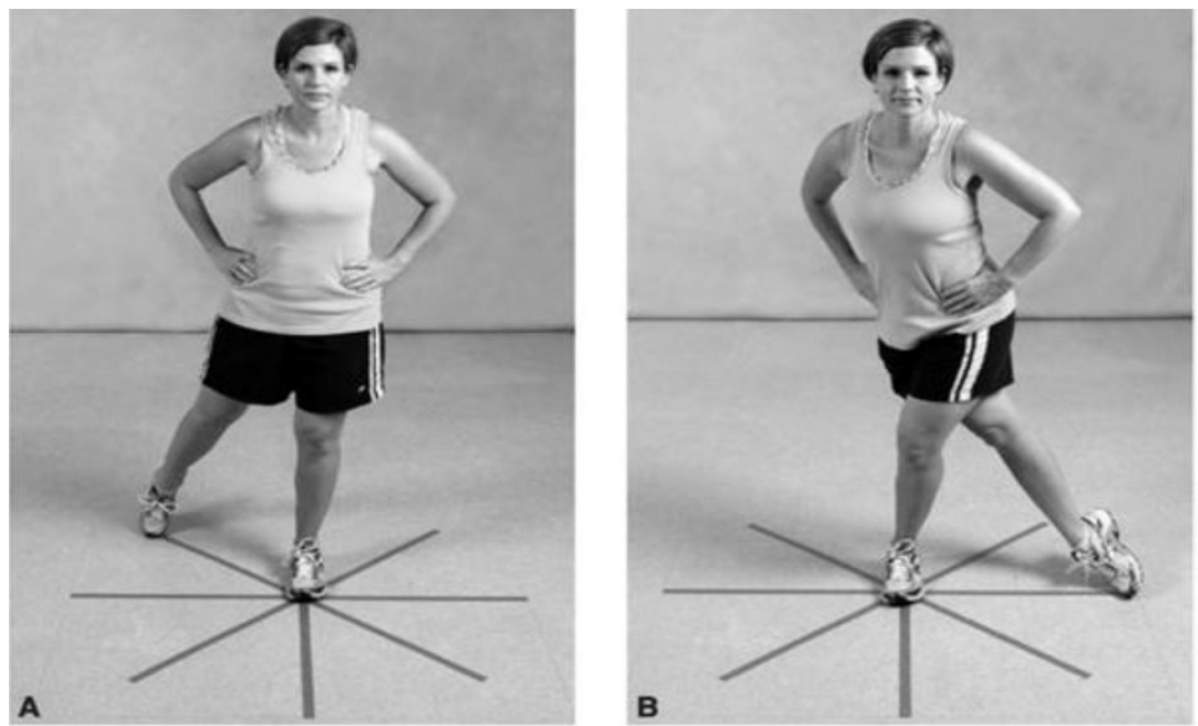

Figura 3: Manutenção do equilíbrio, (A) na diagonal para trás e (B) cruzando atrás da perna estacionária. Fonte: Kisner et al. (2016).

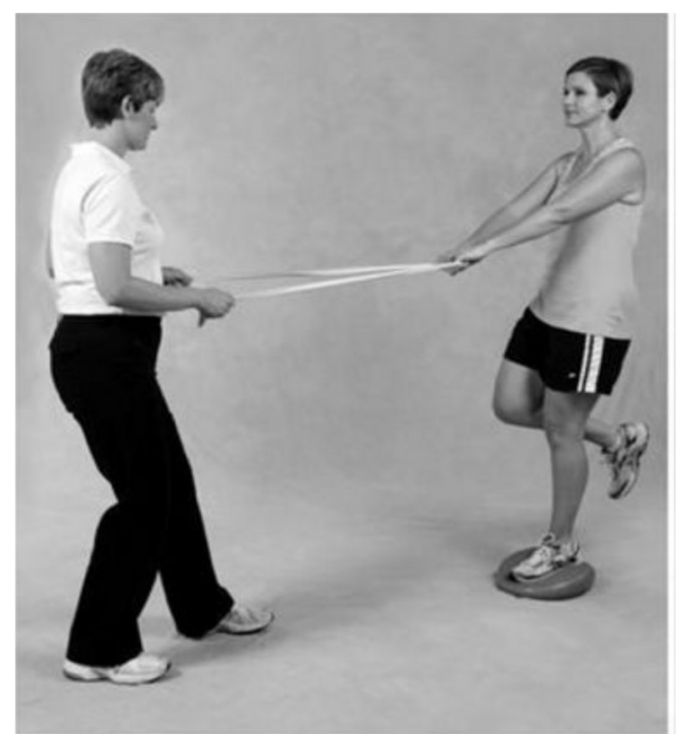

Figura 4: Perturbações em apoio unilateral usando resistência elástica, sobre um disco de equilíbrio. Fonte: Kisner et al. (2016). 

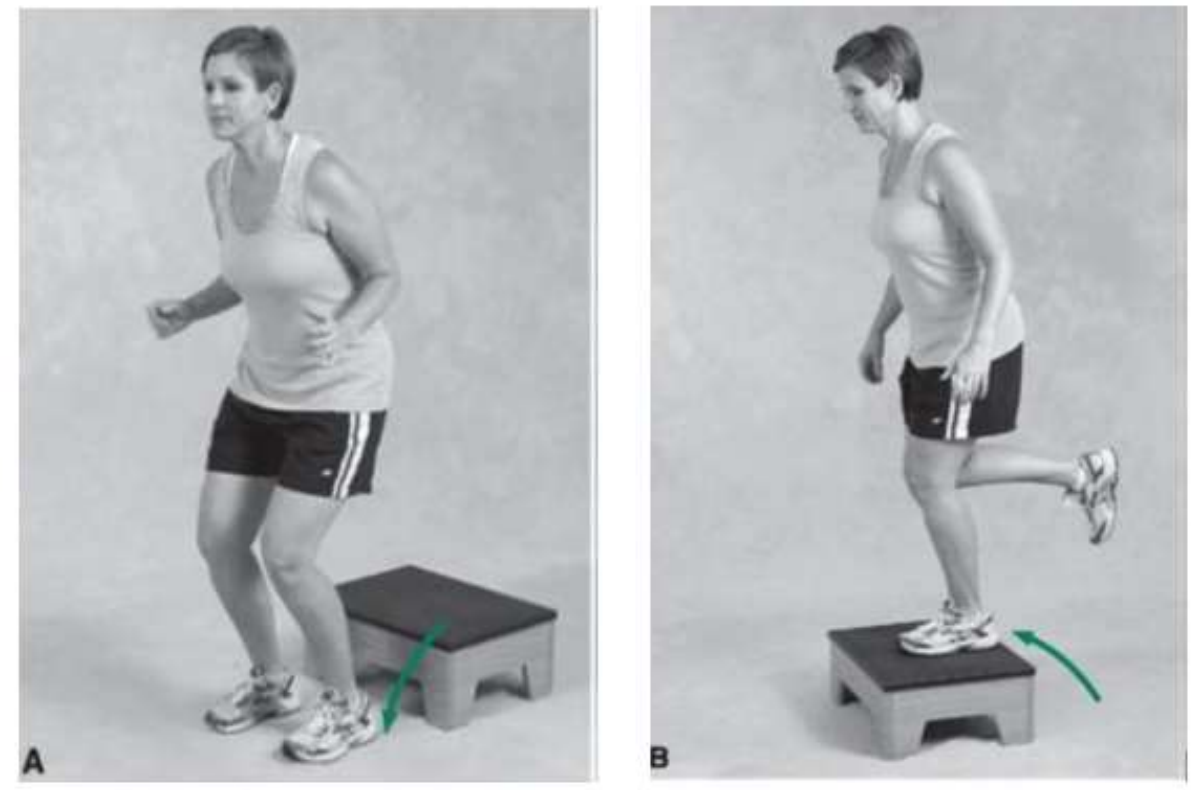

Figura 5: Sequência de saltar e congelar, (A) saltando de um degrau e mantendo a posição final e (B) pulando para cima de um degrau e mantendo a posição final. Fonte: Kisner et al. (2016).

Os três quesitos que estão ligados a performance muscular são potência, força e resistência, sendo eles treináveis para o melhoramento via exercícios resistidos de maneira que a aplicabilidade para o treinamento dos mesmos está coligada aos fatores de intensidade, duração e frequência sendo estrategicamente dosados para potencializar o que for necessário ao paciente, sendo que para diariamente se estabelecem para as atividades um equilíbrio entre força $\mathrm{x}$ potência $\mathrm{x}$ resistência (fadiga) individualmente. Para exemplificar exercícios resistidos indicados para o tratamento das entorses de tornozelo, seguem agora quatro exemplos que foram retirados do livro Exercícios Terapêuticos - Fundamentos e Técnicas (KISNER et al., 2016).

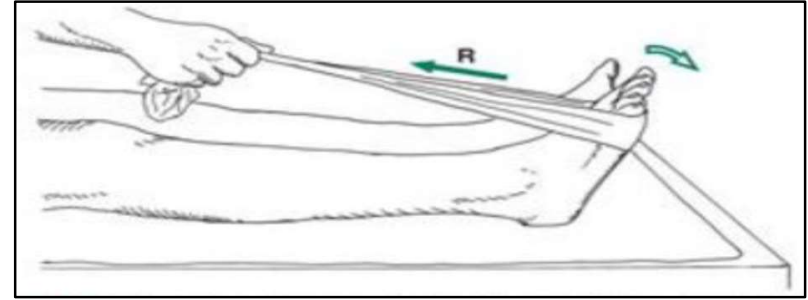

Figura 6: Resistência para os músculos flexores plantares do tornozelo.

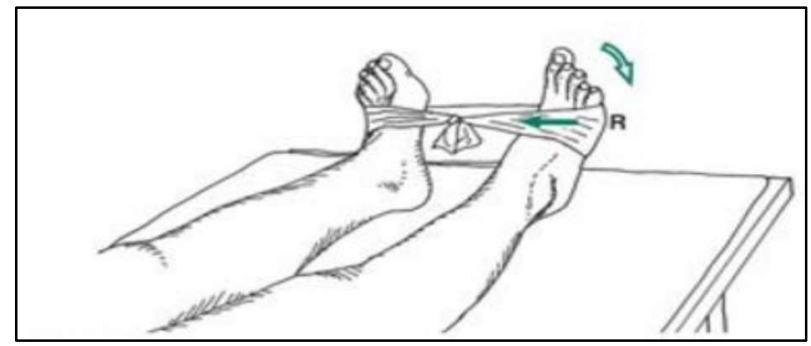

Figura 7: Resistência para os músculos eversores do pé. Fonte: Kisner et al. (2016)

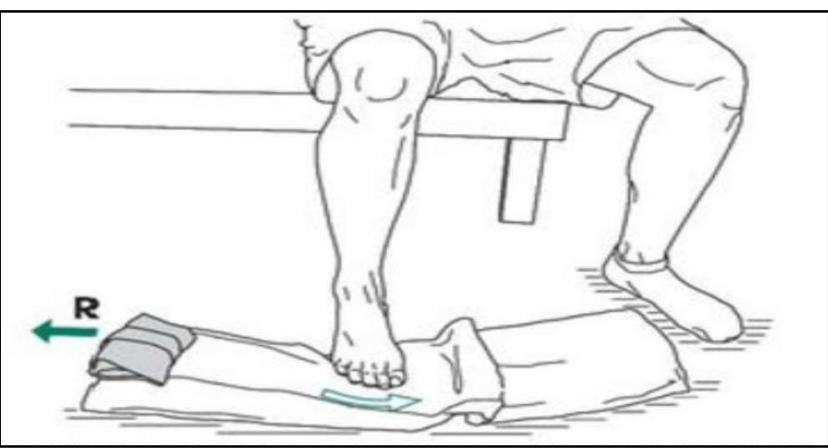

Figura 8: Resistência para abdução e inversão com o peso da ponta da toalha.

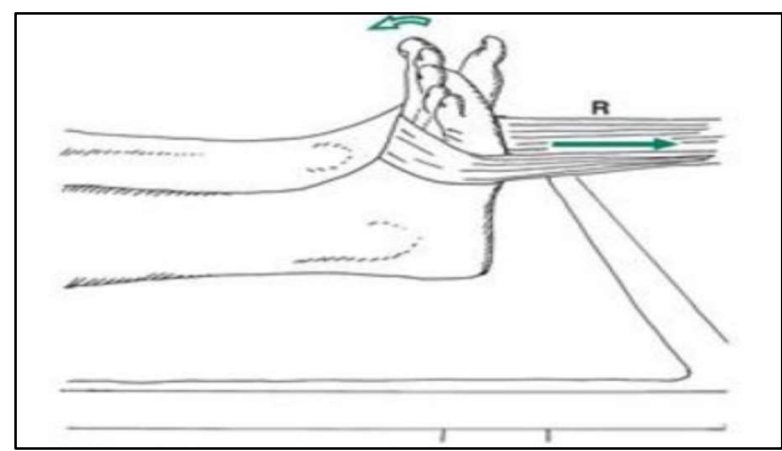

Figura 9: Resistência para os músculos dorsiflexores do tornozelo.

Fonte: Kisner et al. (2016) 


\section{CONCLUSÕES}

O presente estudo é estruturado em sua relevância devido ao alto nível de incidência e recidiva apresentado nas entorses de tornozelo, sobressaindo ainda mais as entorses por quadro de trauma em inversão, sendo que tais fatores desencadeantes levam ao ponto em questão desse trabalho, que é a instabilidade articular demonstrada em inúmeros pacientes que sofreram tal trauma anteriormente. A instabilidade da articulação torna-se então uma importante sequela das entorses, e responsáveis pela continuidade de novos quadros de entorses. Assim, se estabelece um ciclo vicioso de trauma-lesãoconsequência e esse estudo coloca o enfoque sobre essa questão pouco comentada dessa forma, trazendo novamente o assunto para ser estudado e propiciar um raciocino mais aprofundado para o assunto, relevante pela sua ocorrência em indivíduos não atletas, atletas amadores e até em profissionais.

Através desse estudo foi possível esclarecer melhor alguns quesitos que anteriormente não estavam sendo revisados devidamente. A questão sobre a incidência da lesão é apresentada e sendo a mais comum nos esportes, e nos membros inferiores em correlação ao percentual de lesões na área musculoesquelética somente no tornozelo são referentes a $10 \%$ a $30 \%$ e desses valores $25 \%$ são entorses de tornozelo, a colocando assim em patamar de grande prevalência em esportes. As entorses de tornozelo sejam estas em pessoas não praticantes de esportes ou atividades físicas ou atletas em seus respectivos esportes desenvolvem um fator alarmante de $40 \%$ dos indivíduos acometidos apresentarem a instabilidade articular crônica. No tratamento fisioterapêutico, não objetivado aqui neste trabalho o quadro geral das entorses de tornozelo, mas sim na instabilidade articular que tem ocorrência na fase crônica, este se apresenta com concordância com os autores onde é enfatizado a atenção ao fortalecimento adequado da musculatura estabilizadora do tornozelo, sendo estas ligadas aos movimentos de eversão e/ou inversão. Também, apoiado nos trabalhos pesquisados, o treinamento proprioceptivo se faz obrigatório nesta reabilitação.

Encerra-se este enfatizando que através da coleta de dados e informações pesquisadas neste trabalho, que corroboram com a conclusão deste autor, onde se confirmou a alta prevalência de instabilidade articular crônica nas entorses de tornozelo e ainda se indica o tratamento fisioterapêutico baseado em fortalecimento muscular e treinamento proprioceptivo. Ainda se faz necessário mais enfoque no tema apresentado na comunidade cientifica brasileira de fisioterapia, sendo assim há grande espaço para novas pesquisas sobre a instabilidade articular gerada na entorse de tornozelo e geradora de entorses de tornozelo redicivantes, há necessidade de novos estudos para atualização contínua e consequentemente uma melhor atuação com tratamento fisioterapêutico.

\section{REFERÊNCIAS}

ARENA, S. S.; CARAZZATO, J. G.. Estudo epidemiológico das lesões esportivas no basquetebol, futsal e voleibol ocorridos em atletas jovens: aspectos de treinamento e acompanhamento médico. Tese (Doutorado) - Universidade de São Paulo, São Paulo, 2005.

BARONI, B. M.. Adaptações neuromusculares de flexores dorsais e plantares a duas semanas de imobilização após entorse de tornozelo. Rev. Bras. Med. Esporte, v.16, n.5, 2010.

COOK, C. E.; HEGEDUS, E. J.. Testes ortopédicos em

fisioterapia. 2 ed. São Paulo: Manole, 2015.

EMERY, C. A.. Injury prevention and future research. Med Sport Sci., v.49, p.170-91, 2005. 
FONG, D. T. P.; HONG, Y.; SHIMA, Y.; KROSSHAUG, T.; YUNG, P. S.; CHAN, K. M.. Biomechanics of Supination Ankle Sprain: A Case Report of an Accidental Injury Event in the Laboratory. The American Journal of Medicine, v.37, n.4, 2009.

FORTES, C. R.; CARAZZATO, J. G.. Estudo Epidemiológico Da Entorse De Tornozelo Em Atletas De Voleibol De Alto Rendimento. Acta Ortop. Bras., v.16, n.3, 2008.

GARRICK, J. G.. Epidemiologic perspective. Clin. Sports Med., v.7, n.1, p.29-36, 2001

GUYTON, A. C.; HALL, J. E.. Textbook of medical physiology. 11 ed. Philadelphia: WB Saunders, 2006.

HALL, S. J.. Biomecânica básica. 7 ed. Rio de Janeiro: Guanabara Koogan, 2016.

HEBERT, S.; XAVIER, R.. Ortopedia e Traumatologia: Princípios e Prática. 3 ed. São Paulo: Artmed, 2003.

HOGERVORST, T.; BRAND, R. A.. Mechanoreceptors in joint function. J. Bone Joint Surg., v.80, n.9, p.1365-78, 1998.

KISNER, C.; COLBY, L. A.. Exercícios Terapêuticos:

Fundamentos e Técnicas. 6 ed. São Paulo: Manole, 2016.

LASMAR, N. P.; CAMANHO, G. L.; LASMAR, R. C. P.. Medicina do esporte. Rio de Janeiro: Inter, 2002.

LEPORACE, G.; METSAVAHT, L.; SPOSITO, M. M. M.. Importância do treinamento da propriocepção e do controle motor na reabilitação após lesões musculoesqueléticas. Rev. Acta Fisiatr., v.16, n.3, p.126-131, 2009.

MOREIRA, V.; ANTUNES, F.. Entorses do tornozelo do diagnóstico ao tratamento perspectiva fisiátrica. Acta Med. Port., v.21, 2008.

NORONHA, M.; FRANÇA, L. C.; HAUPENTHAL, A.; NUNES, G. S.. Intrinsic predictive factors for ankle sprain in active university students: A prospective study. Scand. J. Med. Sci. Sports, v.23, n.5, p.541-7, 2012.
O'DRISCOLL, J.; DELAHUNT, E.. Neuromuscular training to enhance sensorimotor and functional deficits in subjects with chronic ankle instability: A systematic review and best evidence synthesis. Sports Medicine, Arthroscopy, Rehabilitation, Therapy \& Technology, v.3, n.19, 2011.

PRADO, M. P.; FERNANDES, T. D.; CAMANHO, G. L.; MENDES, A. A. M.; AMODIO, D. T.. Instabilidade mecânica pós-lesão ligamentar aguda do tornozelo. Comparação prospectiva e randomizada de duas formas de tratamento conservador. Rev. Bras. Ortop., v.48, n.4, p.307-316, 2013.

SANTOS, S. G.; PIUCCO, T.; REIS, D. C.. Fatores que interferem nas lesões de atletas amadores de voleibol. Revista Brasileira de Cineantropometria \& Desempenho Humano, Florianópolis, v.9, n.2, 2007.

SOLOMONOW, M.; KROGSGAARD, M.. Sensorimotor control of knee stability. A review. Scand. J. Med. Sci. Sports, v.11, n.2, p.64-80, 2001

STARKEY, C.; RYAN, J. L.. Avaliação de lesões ortopédicas e esportivas. São Paulo: Manole, 2001.

TAKAHASI, H. Y.; VASCONCELLOS, A. A.; SUDA, E. Y.; BACARIN, T. A.; PEREIRA, C. S.; BATTISTELLA, L. R.; KAVAMOTO, C.; LOPES, J. A. F.; VASCONCELOS, J. C. P.. Influência de implementos para o tornozelo nas respostas biomecânicas do salto e aterrissagem no basquete. Rev. Bras. Med. Esporte, São Paulo, v.10, n.6, p.447-452, 2004.

WILLIAMS, G. N.; CHMIELEWSKI, T.; RUDOLPH, K.; BUCHANAN, T. S.; SNYDER-MACKLER, L.. Dynamic knee stability: current theory and implications for clinicians and scientists. J. Orthop. Sports Phys, v.31, n.10, p.546-66, 2001.

ZAMPIERI, C.; ALMEIDA, G. L.. Estudo do controle motor na instabilidade funcional do tornozelo. Dissertação (Mestrado) - Universidade Estadual de São Paulo, Rio Claro, 2000.

ZAMPIERI, C.; ALMEIDA, G. L.. Instabilidade Funcional do Tornozelo: Controle Motor e Aplicação Fisioterapêutica. Rev. Bras. Fisioter., v.7, n.2, p.101-114, 2003.

A CBPC - Companhia Brasileira de Produção Científica (CNPJ: 11.221.422/0001-03) detém os direitos materiais desta publicação. Os direitos referem-se à publicação do trabalho em qualquer parte do mundo, incluindo os direitos às renovações, expansões e disseminações da contribuição, bem como outros direitos subsidiários. Todos os trabalhos publicados eletronicamente poderão posteriormente ser publicados em coletâneas impressas sob coordenação da Sustenere Publishing, da Companhia Brasileira de Produção Científica e seus parceiros autorizados. Os (as) autores (as) preservam os direitos autorais, mas não têm permissão para a publicação da contribuição em outro meio, impresso ou digital, em português ou em tradução. 